\title{
Extremely wicked, shockingly evil and undoubtedly COVID-19: the silent serial killer
}

\author{
Anasuya Guha ${ }^{1}$ (I) Jan Plzak ${ }^{2} \cdot$ Petr Schalek $^{1} \cdot$ Martin Chovanec $^{1}$
}

Received: 14 October 2020 / Accepted: 30 November 2020 / Published online: 3 January 2021

(c) The Author(s), under exclusive licence to Springer-Verlag GmbH, DE part of Springer Nature 2021

\begin{abstract}
Background The SARS-COV-2 virus has more than just an infectious role to play in the society. The rapid spread has also led to significant personal, professional, financial and economic recession globally. Health care professionals are getting seriously compromised due to these issues. No published data are available on the indirect effects of COVID-19 on highrisk medical specialties. Otorhinolaryngology is considered as one such specialty. Hence, we designed a national survey to address these issues.

Materials and methods A google questionnaire was sent to all the otorhinolaryngologists in Czech Republic with the help of the Czech Society of Otorhinolaryngology and Head and Neck Surgery to evaluate the problems they encountered during the first wave of COVID-19. Personal, professional and financial losses were also addressed. Online access to the survey was from 15th April 2020 to 26th April 2020.

Results The psychosomatic indirect impact of the disease affected female doctors than males. Burnout syndrome was the most commonly reported problem. Around $44.75 \%$ of all doctors had a combination of health, financial and economic as well as professional development and educational issues. Doctors from private practices faced higher financial losses.

Conclusions Our study showed that personal, professional and financial disturbances amongst doctors can lead to more serious consequences. With the lack of drastic measures in improving the support system for healthcare workers, the healthcare systems will fail quickly. Adequate support should be made mandatory by health authorities.
\end{abstract}

Keywords Epidemiology $\cdot$ Infection prevention $\cdot$ Health care policy $\cdot$ Psychological impact $\cdot$ Healthcare system $\cdot$ Financial loss $\cdot$ COVID-19

\section{Introduction}

A serial killer is defined as a murderer who repeatedly commits the same offence, typically following a characteristic, predictable behaviour pattern [1]. The World Health Organization officially declared COVID-19 outbreak as a pandemic on 11 March 2020 and since then mortality has been increasing due to the SARS-COV-2 virus [2]. Apart from the rise in

Anasuya Guha

anasuya.guha@outlook.com

1 Department of Otorhinolaryngology, 3rd Faculty of Medicine and University Hospital Kralovske Vinohrady, Charles University, Srobarova 1150/50, Prague 10034, Czech Republic

2 Department of Otorhinolaryngology, Head and Neck Surgery, 1st Faculty of Medicine and University Hospital Motol, Charles University, Prague, Czech Republic fatalities due to the devastating viral infectious outcomes of the disease, the collateral damage associated with it, makes the pandemic even more catastrophic. An overview of the world economic outlook projection shows a global growth projected at $-4.9 \%$, with Advanced Economies at - $8 \%$, Emerging Market and Developing Economies at $-3 \%$ and Low-Income Developing countries at - 1\% [3]. The constant apprehension associated with COVID-19 has led to unparalleled uncertainty in life. The health-related, professional, financial and economic recession are being faced worldwide. Healthcare providers are also incredibly threatened by this and should be protected. A survey done in April 2020 evaluating 724 physicians (75\% related to independent medical practices) reported $97 \%$ of medical practices suffered negative effects either directly or indirectly by COVID- 19 . It showed a decrease in revenue by 55\% and 22\% layoffs amongst medical practices [4]. Another publication also 
discusses the financial issues associated with independent vascular surgeons [5].

The harmful effects related to COVID-19 are also leading to substantial psychological consequences amongst healthcare professionals. An interesting systemic review on mental health outcomes was made in the attempt to assess 5 studies with 3258 healthcare workers (HCWs) reported negative mental health outcomes included stress, depression, anxiety, insomnia [6]. Other similar studies were also published [7, 8].

We found no studies that analysed adverse health, professional, financial problems as a whole amongst specific individual medical specialities. Otorhinolaryngology is considered a significantly high-risk speciality with respect to COVID-19 [9]. In view of these findings, we decided to further evaluate the indirect COVID-19 factors that affected otorhinolaryngologists in Czech Republic.

\section{Materials and methods}

In April 2020, we did a national survey addressing 900 doctors (59.6\% females, $40.4 \%$ males) practicing otorhinolaryngology in Czech Republic and registered with the Czech Society of Otorhinolaryngology and Head and Neck Surgery. A questionnaire using Google forms was designed to evaluate the issues confronted by ENT doctors during the COVID-19 situation. It contained a total of 17 mandatory multiple choice questions and 1 optional question regarding the name of the medical practice. In this paper, we mainly focussed on the questions regarding the most vulnerable areas on the lives of doctors that were affected by the impact of COVID-19, perception of the psychological impact of the pandemic situation, psychosomatic problems experienced by the doctors, the services provided by the workplace if an employee contracts COVID-19 and services that should be available to all ENT doctors. This was translated into Czech language. An online link to the survey was sent via email to all the participants with the help of the Czech Society of Otorhinolaryngology and Head and Neck Surgery. Online access to the survey was from 15th April 2020 to 26th April 2020. Data compilation and statistical analysis were done using Microsoft Excel.

\section{Results}

The survey was completed by 115 female and 66 male doctors, 96 were hospital-based and 85 from private practices. In terms of years of experience in ENT practice after completion of medical school, doctors selected 1 out of 5 divided categories. This showed $18.8 \%$ with $0-5$ years, $8.8 \%$ with $6-10$ years, $24.3 \%$ with $11-20$ years, $32.6 \%$ with $21-35$ years and $15.5 \%$ with $>35$ years of experience.

At least 81 doctors ( $65.4 \%$ were females) selected a combination of health, financial and economic as well as professional development and educational issues with respect to the most significant impact made by the COVID-19 pandemic (Fig. 1). Otherwise, health-related concerns also showed a high priority amongst $38.7 \%$ of the doctors.

A moderate degree of psychological impact of the disease was felt by almost $50 \%$ of the participants (Fig. 2). Amongst 181 doctors, 5 doctors ( $80 \%$ females) found it unbearable or extreme. One had 0-5 years, 2 with 11-20 years and 1 with greater than 35 years of professional experience. Thirty-four doctors experienced severe psychological problems. Eighteen (44.4\% males, 55.5\% females) doctors had more than 21 years of experience and on the other end of the spectrum, eight (12.5\% males, $87.5 \%$ females) doctors working for less than 10 years in ENT had similar issues. In response to further problems encountered personally, six options (none, physical tiredness and exhaustion, mental fatigue and exhaustion, burnout syndrome, combination of all, other) were available, the respondents selected as many
Fig. 1 Impact of COVID-19 on ENT doctors

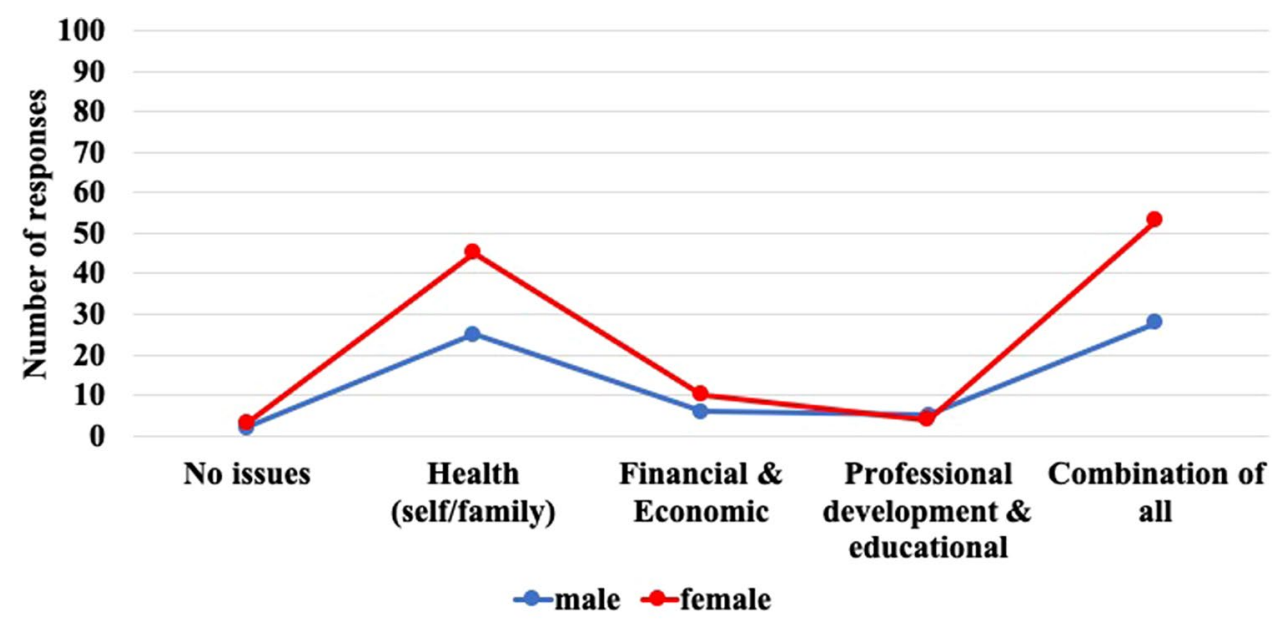


Fig. 2 Psychological impact of COVID-19 on ENT doctors

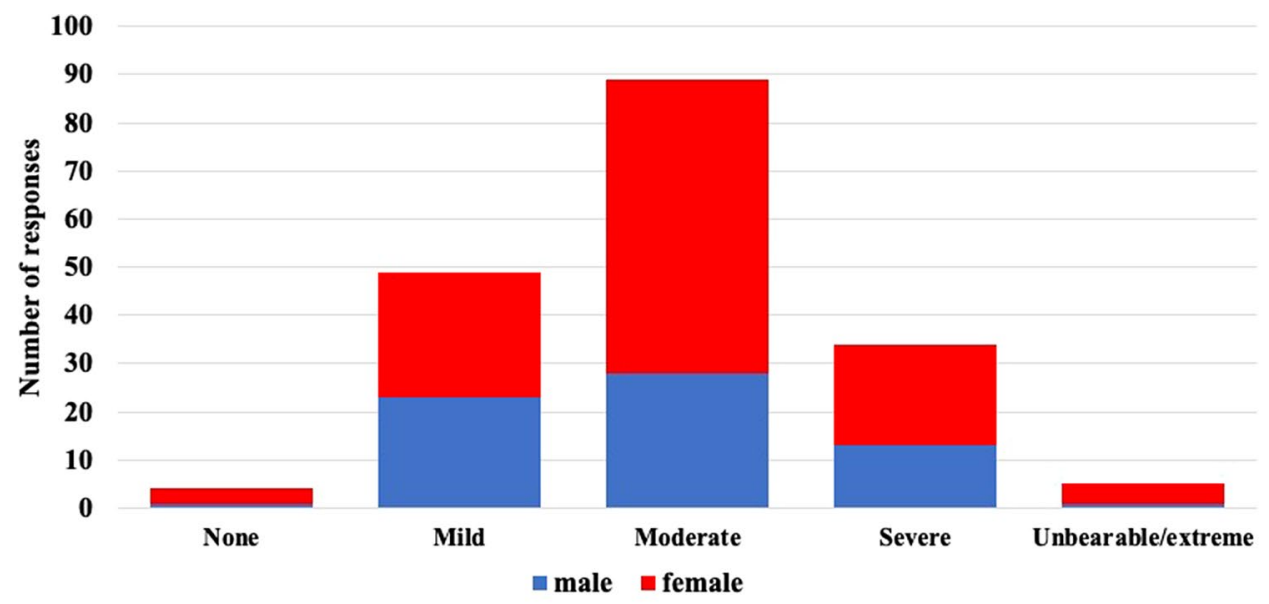

applicable. For purposes of accuracy, the criteria for characterizing burnout syndrome (according to ICD-11) were fulfilled when resulting from chronic workplace stress that had not been successfully managed and characterized by feelings of energy depletion or exhaustion, increased mental distance from one's job, or feelings of negativism or cynicism related to one's job and reduced professional efficacy. Furthermore, if the participant selected other problems, then an open option of entering a comment was given. Results showed ten possible outcomes (Table 1). Three main criteria for health related issues were outcomes 2,3 and 4 . Mental fatigue was the most commonly reported problem either as a single issue or in combination, it was seen in 73 doctors, similarly burnout syndrome was experienced by 23 doctors, and physical tiredness by 20 doctors. Whereas at least 40 doctors selected other problems. The most common self-reported issues were fear, anger, uncertainty and confusion with the situation, dissatisfaction with the health care system, lack of support, disrupted personal life and lack of insight to the future. Furthermore, according to work experience category, one or more issues were experienced by at least $67.6 \%$ with $0-5$ years, $81.3 \%$ with $6-10$ years, $63.6 \%$ with $11-20$ years, $64.4 \%$ with $21-35$ years and $64.2 \%$ with $>35$ years.

In response to the services provided by the employer if an ENT doctor contracts COVID-19, a staggering $42 \%$ of doctors were unaware of any services available to them. Only 21 doctors (11 hospital-based, 10 private practice) stated medical services and 28 doctors ( 8 hospital-based, 20 private practice) had provisions for a combination of medical and financial services (Fig. 3).

With respect to the question addressing services that should be provided by employers, $50.8 \%$ of doctors agreed to all services (Fig. 4).
Table 1 Psychosomatic problems reported during the COVID-19 pandemic

\begin{tabular}{|c|c|c|c|c|c|c|}
\hline & & \multicolumn{5}{|c|}{$\begin{array}{l}\text { Years of experience in Otorhinolaryngology } \\
\text { (number of respondents) }\end{array}$} \\
\hline & & $\begin{array}{l}0-5 \\
(34)\end{array}$ & $\begin{array}{l}6-10 \\
(16)\end{array}$ & $\begin{array}{l}11-20 \\
(44)\end{array}$ & $\begin{array}{l}21-35 \\
(59)\end{array}$ & $\begin{array}{l}>35 \\
(28)\end{array}$ \\
\hline 1 & I have no problems & 11 & 3 & 16 & 21 & 10 \\
\hline 2 & Physical tiredness \& exhaustion & 1 & 2 & 4 & 1 & 1 \\
\hline 3 & Mental fatigue \& exhaustion & 7 & 4 & 12 & 16 & 4 \\
\hline 4 & Burnout syndrome & 2 & 1 & 0 & 3 & 1 \\
\hline 5 & Other problems & 6 & 4 & 9 & 8 & 4 \\
\hline 6 & Combination of $2+3$ & 1 & 0 & 0 & 3 & 2 \\
\hline 7 & Combination of $3+4$ & 5 & 1 & 1 & 4 & 0 \\
\hline 8 & Combination of $3+5$ & 1 & 1 & 1 & 1 & 4 \\
\hline 9 & Combination of $2+3+4$ & 0 & 0 & 1 & 1 & 2 \\
\hline 10 & All of the above problems & 0 & 0 & 0 & 1 & 0 \\
\hline
\end{tabular}


Fig. 3 Support provided by employer if an employee contracts COVID-19
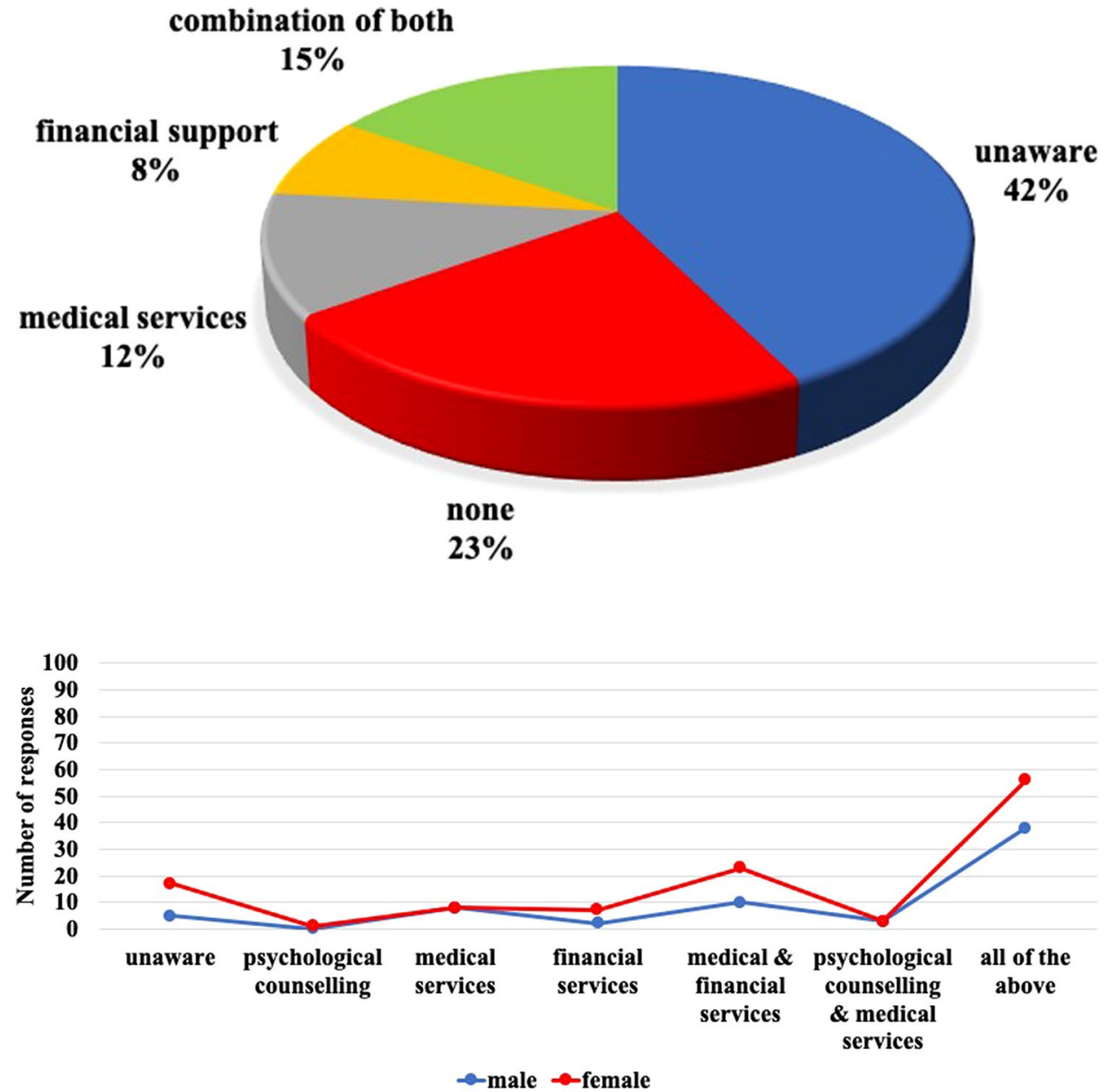

Fig. 4 Suggested services that should be provided by employers

\section{Discussion}

Our study showed a response rate of $20 \%$ only, however given the stressful and unexpected situation faced by ENT practices in Czech Republic, which has never been encountered before, the responses cannot be undermined. A worldwide study done on maxillofacial surgeons had a similar response of $20.2 \%$ [10]. Also of notable interest, is that, our findings showed a higher rate of female respondents, and this may be accounted for, by the higher population of female ENT practitioners in Czech Republic. A greater number of responses was also obtained from hospital-based doctors and those with at least 21-35 years of professional experience. With respect to the most significant impact caused by the COVID-19 pandemic, around $44.75 \%$ of all doctors (53 females, 28 males) selected a combination of health, financial and economic as well as professional development and educational issues. Around $54 \%$ of all respondents experienced financial issues. Owners of private practices had suffered more personal losses due to costs for maintenance, provision of personal protective equipment and so on. They did not receive adequate support. Similar findings were seen in certain studies $[4,5]$.

About 70 doctors were concerned about their health only. This is supported by data that predates COVID-19 and has some significance that fear of ill health on exposure to an infection plays a major role. Authors reported that in the advent of a human pandemic influenza, up to $36 \%$ of HCWs in an Australian tertiary hospital would not attend work and $17 \%$ only after immunizations and /or if antiviral medications were made immediately available, thus bringing about a decrease in almost $53 \%$ of the workforce [11]. More recently, a study done in China amongst 1357 health professionals, more than $85 \%$ described fear of self-infection [12], however this accounts for a larger study group than just doctors.

Amongst 128 participants who reported moderate to unbearable psychological impact related to the COVID19 situation, $67 \%$ were females. The disease had severe psychological impact on 15 doctors $(66.7 \%$ females) and unbearable psychological impact on 5 doctors $(60 \%$ 
females), and interestingly these findings were related to doctors with less than 21 years of professional experience.

Certain studies had similar findings of women, young age, married and frontline workers being more susceptible to severe mental health problems [6-8]. Even though we had more female participants, the pattern is similar.

Whilst evaluating additional personal problems in our study, 64.2-81.3\% doctors reported at least one psychosomatic issue, either singly or in combination. Mental fatigue was the most commonly described problem, followed by burnout syndrome and physical tiredness. Amongst all doctors, $22 \%$ selected other problems too. An evaluation of 3599 Northern Italian dentists found fatigue as one of the most common symptoms suffered [13]. A multinational, multicentre study amongst $906 \mathrm{HCWs}$ in Singapore and India found at least $66.7 \%$ experiencing one symptom, physical or psychological; $19.4 \%$ had anxiety and at least $13.6 \%$ had depression [7]. Another systemic review and meta-analysis evaluated 13 studies (a combined total of 33,062 HCWs) with a pooled prevalence of $23.1 \%$ with anxiety in 12 studies, $22.8 \%$ with depression in 10 studies and $34.32 \%$ with insomnia in 5 studies [8]. These findings were also corroborated by a study amongst Chinese surgical staff [14].

Only $15 \%$ of our study group reported access to medical and financial support if an employee contracts COVID19 , and unfortunately most were unaware of any support services. This is a dire finding, because there is a real risk of reduction in physicians due to the disease or the fear of contracting it. Although in Czech Republic, individual hospitals recommended that doctors above the age of 65 years and or those who are immunocompromised had the option of home office with certain compensation, this was optional and not mandatory. Furthermore, doctors working or owning private practices had almost no support therefore they were continually exposed to the disease. The study done amongst medical practices in USA has shown a real healthcare workforce shortage of 22\% layoffs and $48 \%$ furloughs in April 2020 with an increased prediction of $36 \%$ and $60 \%$ respectively in May 2020 [4]. Accordingly, it could be worse in low-income countries, as was seen during the Ebola virus epidemic in West Africa [15].

In terms of support that should be provided to all ENT doctors, 58 of them agreed on health services and 48 expected financial support and 92 agreed on all services including psychological counselling. To help healthcare systems, USA has signed the Coronavirus Aid, Relief and Economic Security (CARES) Act providing 100 billion dollars to the Department of Health and Human Services to reimburse eligible health care providers for healthcarerelated expenses or lost revenues attributed to COVID-19 [5]. Europe has decided to provide incentives for surge capacity like Germany pays hospitals 50,000 Euros for each new intensive care unit bed, Netherlands receives 10 Euros for each registered patients and so on. Supplementary payments have been promised to several European countries. Ireland has made agreements with private hospitals to draw on their spaces, supplies and staff, so that these premises are accessible to the whole population [16]. Maintenance and effective functioning of health care systems are the key elements in every society worldwide. A strong backbone of support will always be required, without which, the consequences would be irreparable and disastrous. Furthermore, a large part of maintaining good physical and mental health amongst HCWs, more so amongst high-risk specialties such as Otorhinolaryngology, should be made a priority. Mandatory health checks and evaluation of psychological status in healthcare professionals should be done, where appropriate, with the help of questionnaires [6]. This would also help with early recognition of problems, thus maintaining healthcare quality and decreasing the risk of reduced staffing during a pandemic situation.

\section{Conclusion}

All protective measures and equipment should be provided by employers to reduce undue risk and ensure safe practice amongst otorhinolaryngologists. Local health authorities should be assigned and dedicated in helping practices with little or no support. The vicious cycle or trend with personal (physical and mental health) problems, professional issues and financial insecurity can pose a psychological threat and must be taken very seriously. If any deteriorating factor is discovered that may compromise the health or professional continuity of an ENT doctor, then appropriate measures such as leave, counselling or health support and or financial compensation should be made to reduce the risk of self-harm, detriment to the profession and near ones. Appropriate special funds should be set aside for emergency needs and reimbursement of COVID-19-related damages. These measures will also help reduce the risk of mortality directly and indirectly associated with COVID-19. The lessons learnt from the first attack of the COVID-19 pandemic ought to serve as invaluable tools to avoid repeating the same oversights. Fear is the epitome of poor performance in any profession. Psychosomatic problems are rising amongst health providers due to the failure in identifying and eliminating causative factors. Such health problems are linked to financial problems and vice versa. ENT is a high-risk department with respect to COVID-19 and are facing unparalleled clinical challenges on a daily basis. The care of non-covid-19 seriously ill patients is also of grave concern in centres where medical supplies are deficient. Financial detriment will lead to further redundancy and deprivation, more so amongst most private practices. With the lack of drastic measures in improving the support system for healthcare workers in 
countries such as Czech Republic, the healthcare systems will fail quickly.

Funding No funding was received.

Availability of data and material Available on request.

\section{Compliance with ethical standards}

Conflicts of interest The authors declare that they have no conflict of interest.

Research involving human participants and/or animals Formal ethical approval was not required for this survey since it was questionnaire based. Protocol followed in studies involving human subjects were in compliance with the Helsinki declaration and further in accordance with local ethical guidelines of the institutional ethical committee of 3rd faculty of Medicine, Charles University, Prague, Czech Republic. Furthermore it was also approved by the Czech Society of Otorhinolaryngology and Head and Neck Surgery.

Informed consent Not applicable; completion of online survey implied consent to participate. All participants have been kept anonymous.

\section{References}

1. Oxford reference (2006) Serial killer In: The Oxford Dictionary of Phrase and Fable, 2nd edn. Oxford University Press. https:// www.oxfordreference.com/view/10.1093/oi/authority.2011081010 5826126. Accessed 27 Aug 2020

2. WHO (2020) Coronavirus disease (COVID-19) situation reports. https://www.who.int/emergencies/diseases/novel-coronaviru s-2019/situation-reports. Accessed 27 Aug 2020

3. A Crisis Like No Other, An Uncertain Recovery (2020) World Economic Outlook Update. International Monetary Fund. https:// www.imf.org/en/Publications/WEO/Issues/2020/06/24/WEOUp dateJune2020. Accessed 2 Sep 2020

4. COVID-19 financial impact on medical practices (2020) Medical Group Management Association. https://mgma.com/getat tachment/9b8be0c2-0744-41bf-864f-04007d6adbd2/2004-G0962 1D-COVID-Financial-Impact-One-Pager-8-5. Accessed 2 Sep 2020

5. Satiani B, Zigrang TA, Bailey-Wheaton JL (2020) COVID19 financial resources for physicians. J Vasc Surg. https://doi. org/10.1016/j.jvs.2020.04.482

6. Talevi D, Socci V, Carai M et al (2020) Mental health outcomes of the CoViD-19 pandemic. Riv Psichiatr 55(3):137-144. https:// doi.org/10.1708/3382.33569
7. Chew NWS, Lee GKH, Tan BYQ et al (2020) A multinational, multicentre study on the psychological outcomes and associated physical symptoms amongst healthcare workers during COVID-19 outbreak. Brain Behav Immun 88:559-565. https:// doi.org/10.1016/j.bbi.2020.04.049

8. Pappa S, Ntella V, Giannakas T et al (2020) Prevalence of depression, anxiety, and insomnia among healthcare workers during the COVID-19 pandemic: a systematic review and meta-analysis. Brain Behav Immun 88:901-907. https://doi.org/10.1016/j. bbi.2020.05.026

9. Guha A, Plzak J, Chovanec M (2020) Face to face with COVID19: highlights of challenges encountered in various ENT practices across the Czech Republic (a national survey) [published online ahead of print, 2020 Aug 19]. Eur Arch Otorhinolaryngol 2020:1-6. https://doi.org/10.1007/s00405-020-06280-5

10. Maffia F, Fontanari M, Vellone V et al (2020) Impact of COVID19 on maxillofacial surgery practice: a worldwide survey. Int $\mathbf{J}$ Oral Maxillofac Surg 49(6):827-835. https://doi.org/10.1016/j. ijom.2020.04.015

11. Martinese F, Keijzers G, Grant S, Lind J (2009) How would Australian hospital staff react to an avian influenza admission, or an influenza pandemic? Emerg Med Australas 21(1):12-24. https://doi.org/10.1111/j.1742-6723.2008.01143.x.PMID:19254 308;PMCID:PMC7163727

12. Zhang M, Zhou M, Tang F et al (2020) Knowledge, attitude, and practice regarding COVID-19 among healthcare workers in Henan. China J Hosp Infect 105(2):183-187. https://doi. org/10.1016/j.jhin.2020.04.012

13. Cagetti MG, Cairoli JL, Senna A et al (2020) COVID-19 outbreak in North Italy: an overview on dentistry. A questionnaire survey. Int J Environ Res Public Health 17(11):3835. https://doi. org/10.3390/ijerph17113835

14. Xu J, Xu QH, Wang CM et al (2020) Psychological status of surgical staff during the COVID-19 outbreak. Psychiatry Res 288:112955. https://doi.org/10.1016/j.psychres.2020.112955

15. Bong CL, Brasher C, Chikumba E et al (2020) The COVID-19 pandemic: effects on low- and middle-income countries. Anesth Analg. 131(1):86-92. https://doi.org/10.1213/ANE.0000000000 004846

16. Sarah Thomson et al., WHO (2020) Strengthening the health financing response to COVID-19 in Europe. SPARC. https://sparc .africa/resource/strengthening-the-health-financing-response-tocovid-19-in-europe-sarah-thomson-et-al-world-health-organizati on/

Publisher's Note Springer Nature remains neutral with regard to jurisdictional claims in published maps and institutional affiliations. 